\title{
Label-free infrared spectroscopic imaging for characterization of necrotic tissue areas on cutaneous squamous cell carcinoma
}

\author{
Cássio A. Lima \\ Instituto de Pesquisas Energéticas e Nucleares \\ Luciana Correa \\ University of São Paulo \\ Hugh Byrne \\ Technological University Dublin, hugh.byrne@tudublin.ie
}

See next page for additional authors

Follow this and additional works at: https://arrow.tudublin.ie/biophoncon

Part of the Physics Commons

\section{Recommended Citation \\ Cássio A. Lima, Luciana Correa, Hugh J. Byrne, Denise M. Zezell, "Label-free infrared spectroscopic imaging for characterization of necrotic tissue areas on cutaneous squamous cell carcinoma," Proc. SPIE 10868, Advanced Biomedical and Clinical Diagnostic and Surgical Guidance Systems XVII, 1086812 (26 February 2019); DOI: 10.1117/12.2510711}

This Conference Paper is brought to you for free and open access by the DIT Biophotonics and Imaging at ARROW@TU Dublin. It has been accepted for inclusion in Conference Papers by an authorized administrator of ARROW@TU Dublin. For more information, please contact arrow.admin@tudublin.ie, aisling.coyne@tudublin.ie,gerard.connolly@tudublin.ie.

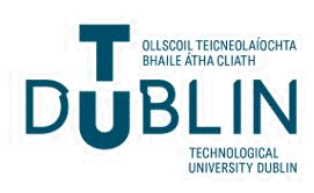




\section{Authors}

Cássio A. Lima, Luciana Correa, Hugh Byrne, and Denise M. Zezell 


\title{
Label-free Infrared spectroscopic imaging for characterization of necrotic tissue areas on cutaneous squamous cell carcinoma
}

\author{
Cassio A. Lima ${ }^{a}$, Luciana correa ${ }^{b}$, Hugh J. Byrne ${ }^{c}$, Denise M. Zezell*a \\ ${ }^{a}$ Instituto de Pesquisas Energeticas e Nucleares (IPEN-CNEN/SP), University of Sao Paulo, Av. \\ Prof. Lineu Prestes 2242, Sao Paulo, SP Brazil 05508-00 \\ ${ }^{\mathrm{b}}$ Faculdade de Odontologia, University of Sao Paulo, Av. Prof. Lineu Prestes 2227, Sao Paulo, SP \\ Brazil 05508-00 \\ ${ }^{c}$ FOCAS Research Institute, Dublin Institute of Technology, DIT Kevin St, Dublin, Limerick \\ Ireland Dublin 8
}

\begin{abstract}
In this study, FTIR spectroscopy was used to evaluate the overall biochemical status of necrotic tissue areas of cutaneous squamous cell carcinoma chemically-induced on mice. FTIR hyperspectral image collected from specimen showed high correlation with the photomicrograph obtained by light microscopy, in which we were able to identify clusters associated to keratin, necrosis and regions with no tissue. Alterations in the protein content were documented in the necrotic tissue areas, indicating changes on protein conformation.
\end{abstract}

Keywords: FTIR microspectroscopy, cutaneous squamous cell carcinoma, death mechanisms, necrosis, KMCA

*zezell@usp.br; phone +55 1131339255

\section{INTRODUCTION}

Fourier Transform Infrared (FTIR) spectroscopy is a label-free analytical technique able to provide information about the common molecular units of tissue samples (carbohydrates, proteins, lipids and nucleic acids) based on its chemical vibrations that are infrared active [1]. In the last years, many proof-of-concept studies have been performed using the spectral signatures measured by FTIR spectroscopy for the diagnosis of cancerous and non-cancerous diseases as well as to monitor the effects of drug treatments on disease progression/regression [2-6]. However, few studies have focused on evaluate the spectrochemical signatures of necrotic cell death. Necrosis is a nonspecific mode of cell death induced by different factors that lead to the irreversible cell injury such as mechanical injury, infections, hypoxia, and a variety of toxic chemicals. Cell death caused by necrosis is accompanied by ion and water efflux and dispersal of organelles, resulting in a rupture of cytoplasmic and nuclear membranes, the swelling of mitochondria, and the flocculation of chromatin [7]. The techniques routinely used to study the cellular and molecular mechanisms triggered by necrosis may include histological examination of tissue biopsies, immunohistochemistry (IHC), in-situ hybridization (ISH), polymerase chain reaction (PCR), etc. These methods are laborious, time-consuming and require multiple assays/staining. Thus, the present study aims to evaluate the spectrochemical signatures of necrotic tissue areas on cutaneous squamous cell carcinoma in order to develop FTIR microspectroscopy as a new optical diagnostic tool to support conventional lightscopic and molecular techniques to understand the mechanisms associated to necrotic cell death.

\section{MATERIAL AND METHODS}

\subsection{Chemical carcinogenesis}

After approval by the Committee on Animal Research and Ethics (164/15-CEUA-IPEN/SP), female Swiss mice aged up to 10 weeks and body mass about $25 \mathrm{~g}$ were submitted to a well-established two-stage chemical carcinogenesis protocol. In the first phase (induction), the shaved backs of the animals were submitted to a single dose of 7,12dimethyl-benzanthracene (DMBA, CAS number 57-59-6, Merck KGaA, Darmstadt, Germany) (50 $\mu \mathrm{g}$ diluted in $200 \mu \mathrm{l}$ of acetone). After one week, the second phase of the protocol was initiated (promotion), in which the animals underwent twice a week to applications of 12-O-tetradecanoyl-phorbol-13 acetate (TPA, CAS number 16561-29-8, Merck KGaA, Darmstadt, Germany) (5 $\mu$ g diluted in $200 \mu \mathrm{L}$ acetone) during 12 months [8]. In the first phase of the 
experiment, animals were submitted to general anesthesia using ketamine $(0.001 \mathrm{ml} / \mathrm{g})$ and xylazine $(0.0005 \mathrm{ml} / \mathrm{g})$ intraperitoneally applied. The whole procedure for the application of the carcinogens were performed in a laminar flow to ensure the safety of the manipulator. Animals were euthanized at the end of experiment via overdose of anesthetics and the cutaneous tissues were extracted with a scalpel.

\subsection{Sample preparation}

Specimens extracted from animals were formalin-fixed for 24 hours, diaphanized in two baths of pure xylol for 30 minutes, dehydrated in ethanol baths with increasing concentrations (50,70 and 100\%) and paraffin-embedded (FFPE). Two adjacent histological slices ( 5 and $10 \mu \mathrm{m}$ thickness each) were obtained using a microtome. The first slice $(5 \mu \mathrm{m}$ thickness) was prepared in a conventional glass slide, hematoxylin and eosin (H\&E) stained according to the international standards and coverslipped. The second slice $\left(10 \mu \mathrm{m}\right.$ thickness) was placed on calcium fluoride $\left(\mathrm{CaF}_{2}\right)$ substrates (Crystran Ltda., Poole, Dorset, UK). No chemical dewaxing or chemical staining was performed on the second slice and it was not coverslipped. Specimens H\&E stained were examined by a pathologist.

\subsection{FTIR spectroscopy}

\section{Data acquisition}

FTIR hyperspectral images were acquired in transmission mode using a Spotlight 400N FTIR imaging system (Perkin Elmer, Waltham, MA, USA) equipped with an AutoImage microscope system operating with a $\times 40$ Cassegrain objective. Spectral measurements were acquired over the spectral range $750-4000 \mathrm{~cm}^{-1}$ with a pixel size of $6.25 \mu \mathrm{m} \times$ $6.25 \mu \mathrm{m}$ at a spectral resolution of $4 \mathrm{~cm}^{-1}$. Background measurements were acquired on a region with no tissue with 120 scans per pixel whereas 8 scans per pixel were recorded from the sample.

\section{Data pre-processing and Spectral analysis}

FTIR spectra were vector normalised and smoothed with Savitzky-Golay filter using a polynomial of second order in an eleven-point window. RMie-EMSC algorithm was applied to the images aiming to correct dispersive effects induced by resonant Mie scattering. FTIR images were segmented/reconstructed via K-means clustering analysis (KMCA) using the spectral region over the range $1000-1800 \mathrm{~cm}^{-1}$. The reconstructed image were compared to photomicrographs acquired from H\&E stained specimens in order to identify the clusters associated to necrotic areas. All pre-processing steps and spectral analysis were performed using Matlab® R2015 (MathWorks, Natick, MA, USA).

\section{RESULTS}

Figure 1 depicts a photomicrograph obtained by light microscopy from a histological section of a specimen collected from a mouse submitted to 12 months of chemical carcinogenesis. The lesion was classified as invasive squamous cell carcinoma based on the microscopic histological aspects observed. The specimen depicts intense epithelial hyperplasia with solid pattern of invasiveness (arrow), poor connective tissue with intense inflammation (arrow), extensive areas of necrotic tissue $(*)$ and hyperkeratinization (pentagram). 


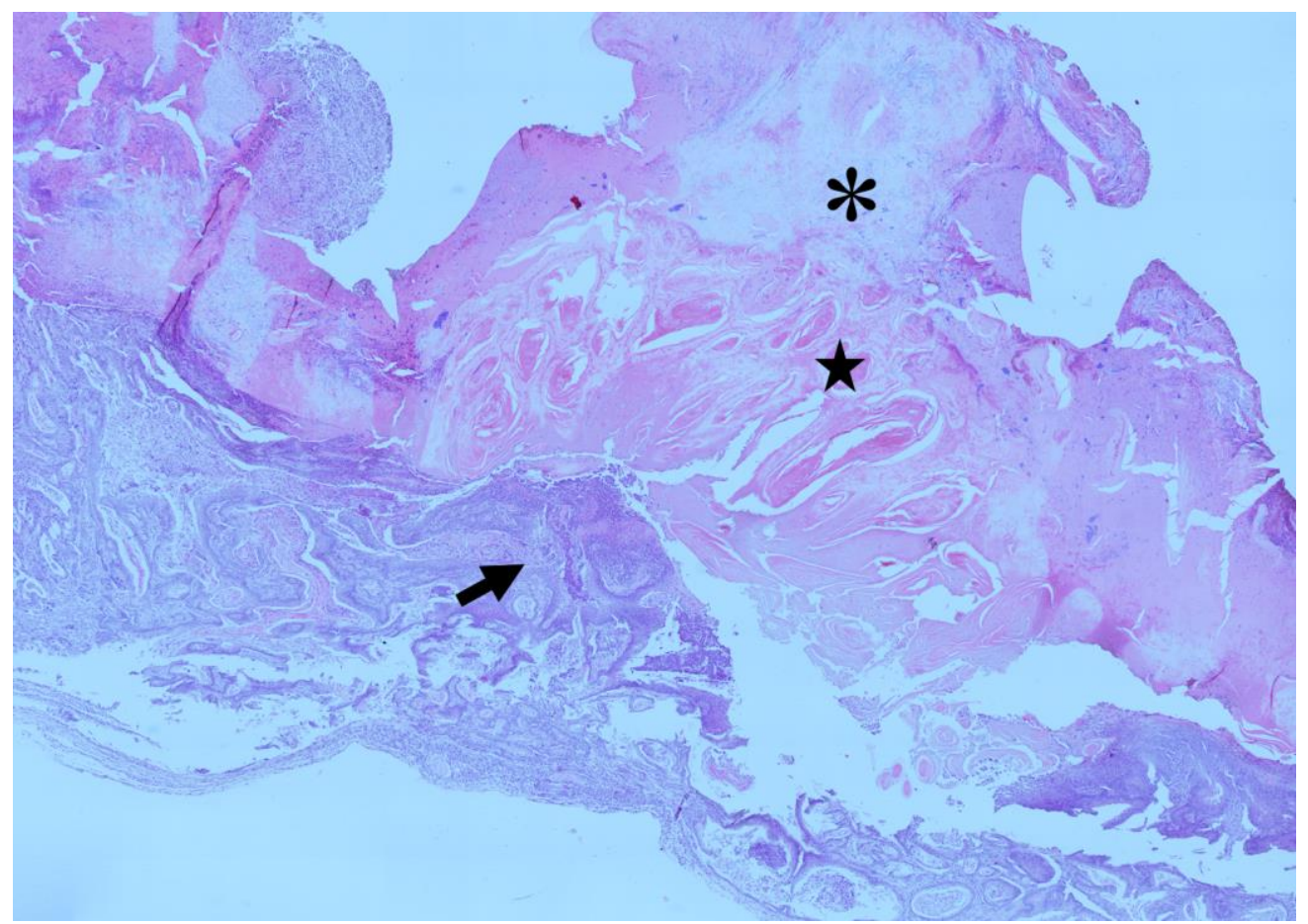

FIGURE 1. Representative histopathology aspect presented by histological specimen stained by hematoxylin and eosin (100X original magnification). (*): Necrotic tissue. (pentagram): Hyperkeratinization. (Arrow): Intense inflammation and epithelial hyperplasia.

A FTIR hyperspectral image was collected from a specific region of the histological specimen exhibiting intense keratinization and keratin pearls surrounded by extensive area of necrosis (Figure 2.A) in order to evaluate the spectroscopic profile of necrotic tissue. Figure 2.B and $\mathrm{C}$ show the chemical map and the reconstructed image obtained using KMCA (4 clusters) as segmentation algorithm. 

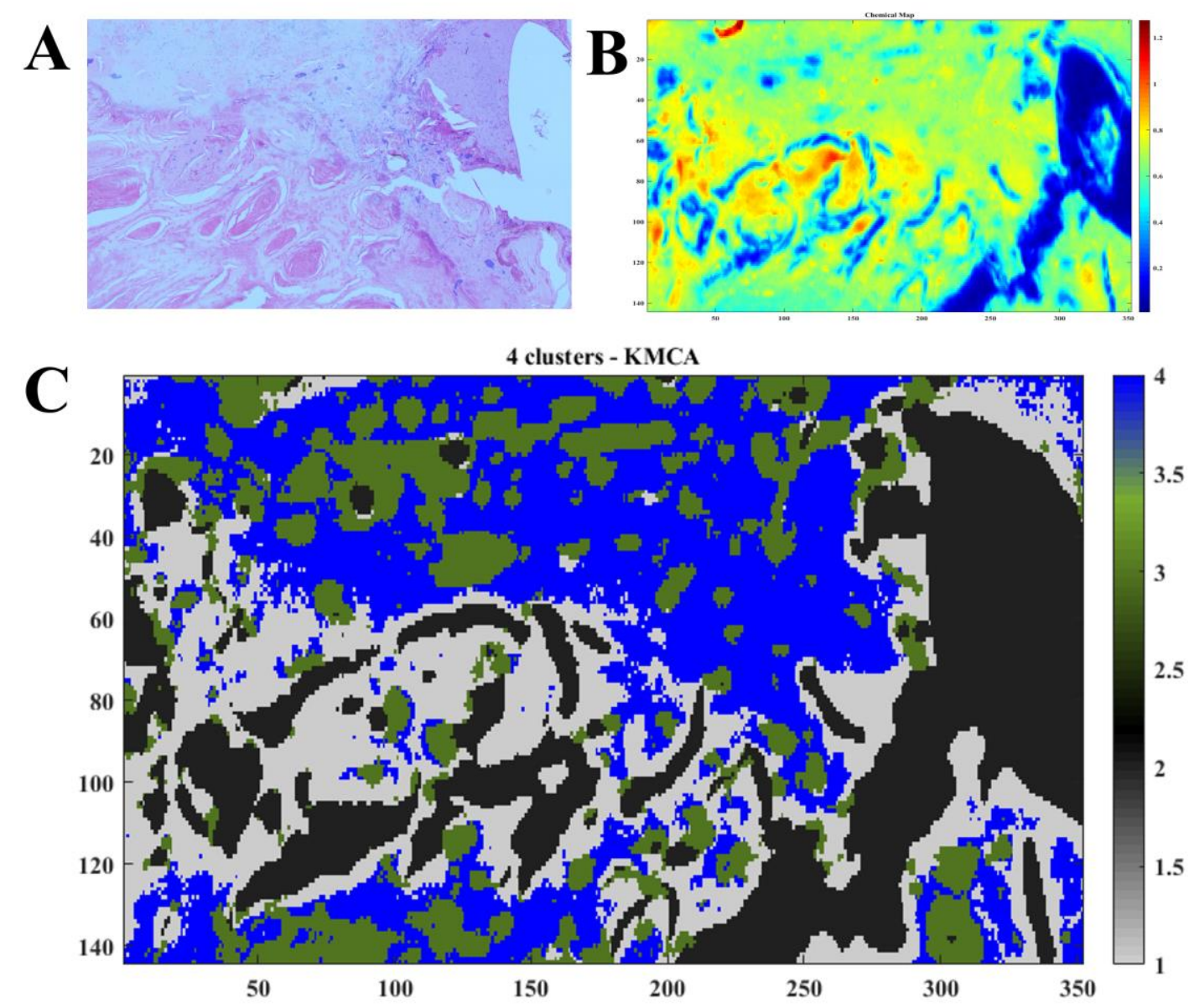

FIGURE 2. A:Representative histopathology aspect presented by histological specimen stained by hematoxylin and eosin (100X original magnification). B: Chemical map. C: Hyperspectral image reconstructed using K-means cluster analysis

At a first glance, the FTIR image and the photomicrograph obtained by light microscopy are highly correlated. The necrotic area is depicted by blue pixels (cluster 4), keratin regions are represented by green pixels (cluster 3), regions of no tissue are colored in black (cluster 2) and grey pixels represent regions of mixed keratin and necrosis (cluster 1). Figure 3 shows the averaged second derivative obtained for each cluster. 


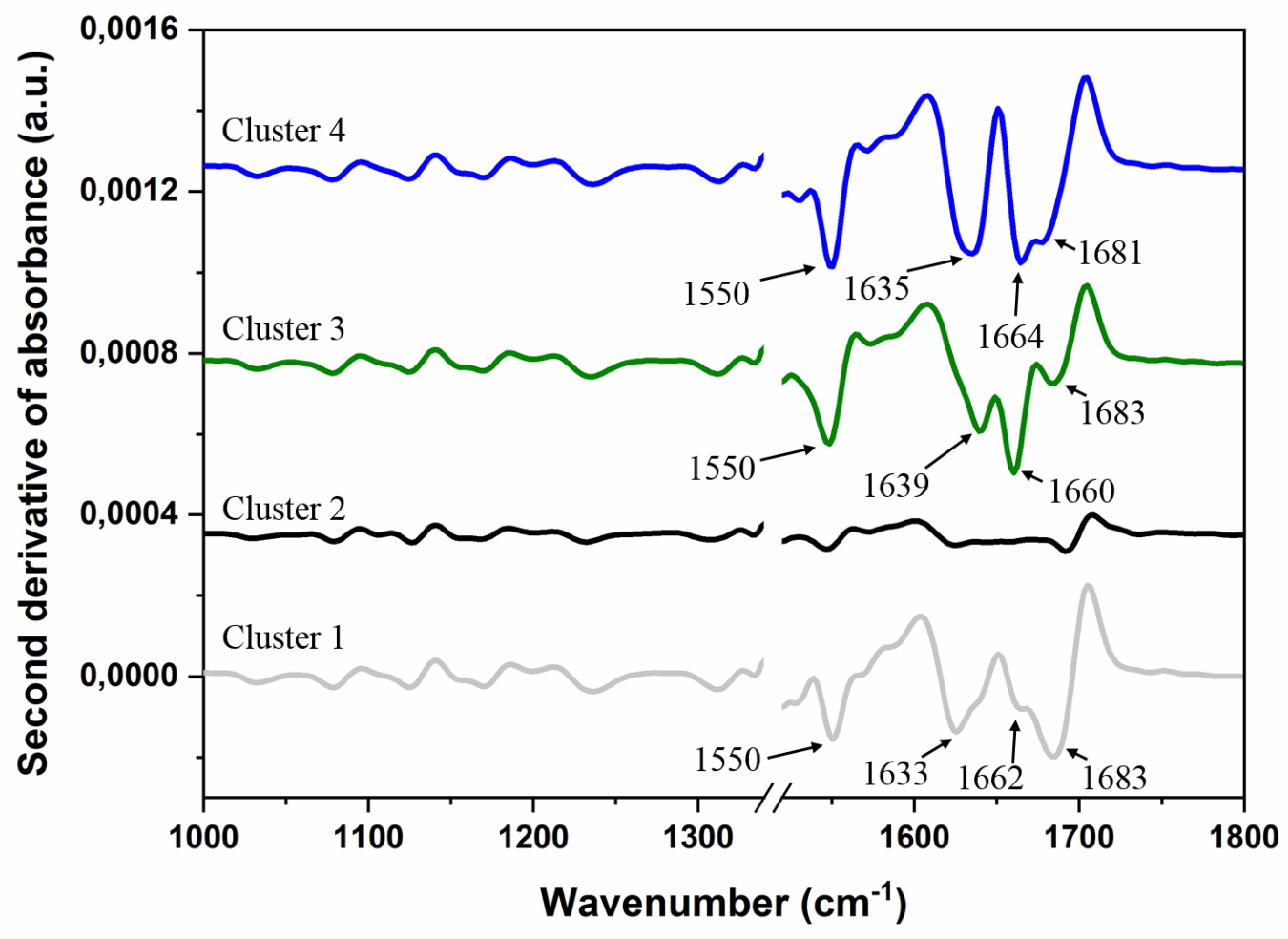

FIGURE 3. Fingerprint region $\left(1000-1800 \mathrm{~cm}^{-1}\right)$ of averaged second derivatives of each cluster obtained by KMCA.

Changes on vibrational modes over $1000-1400 \mathrm{~cm}^{-1}$ (carbohydrates, fibrous structure of proteins and nucleic acids) were not observed. Spectral region over $1500-1800 \mathrm{~cm}^{-1}$ comprises vibrations associated to protein content (Amide II: $1550 \mathrm{~cm}^{-1}$ and the sub-bands of Amide I: $\alpha$-helix, $1660-64 \mathrm{~cm}^{-1} ; \beta$-sheet, $1633-39$ and random coils/turns: $1681-83 \mathrm{~cm}^{-1}$ [9]. Significant alterations were identified in the protein content region. Spectral signatures associated to secondary structure of proteins as well as to Amide II presented increased absorption intensities in the necrotic tissue areas as well as shifts on band peak position, indicating changes on protein conformation.

\section{CONCLUSIONS}

In this study, FTIR spectroscopy was used to evaluate the overall biochemical status of necrotic tissue areas of cutaneous squamous cell carcinoma chemically-induced on mice. FTIR hyperspectral image collected from specimen showed high correlation with the photomicrograph obtained by light microscopy, in which we were able to identify clusters associated to keratin, necrosis and regions with no tissue. Alterations in the protein content were documented in the necrotic tissue areas, indicating changes on protein conformation.

\section{REFERENCES}

[1] Baker, M. J., Trevisan, J., Bassan, P. et al., "Using Fourier transform IR spectroscopy to analyze biological materials," Nat Protoc, 9(8), 1771-91 (2014).

[2] Lima, C. A., Goulart, V. P., Correa, L. et al., "ATR-FTIR spectroscopy for the assessment of biochemical changes in skin due to cutaneous squamous cell carcinoma," Int J Mol Sci, 16(4), 6621-30 (2015). 
[3] Pereira, T. M., Zezell, D. M., Bird, B. et al., "The characterization of normal thyroid tissue by micro-FTIR spectroscopy," Analyst, 138(23), 7094-100 (2013).

[4] Lima, C. A., Goulart, V. P., Correa, L. et al., "Using Fourier transform infrared spectroscopy to evaluate biological effects induced by photodynamic therapy," Lasers Surg Med, 48(5), 538-45 (2016).

[5] Diem, M., Mazur, A., Lenau, K. et al., "Molecular pathology via IR and Raman spectral imaging," J Biophotonics, 6(11-12), 855-86 (2013).

[6] Paraskevaidia, M., Morais, C. L. M., Lima, K. M. G. et al., "Differential diagnosis of Alzheimer's disease using spectrochemical analysis of blood," Proc Natl Acad Sci USA, 114(38), 10 (2017).

[7] Yamada, T., Miyoshi, N., Ogawa, T. et al., "Observation of molecular changes of a necrotic tissue from a murine carcinoma by Fourier-transform infrared microspectroscopy,” Clin Cancer Res, 8, 2010-2014 (2002).

[8] Abel, E. L., Angel, J. M., Kiguchi, K. et al., "Multi-stage chemical carcinogenesis in mouse skin: fundamentals and applications," Nat Protoc, 4(9), 1350-62 (2009).

[9] Talari, A. C. S., Martinez, M. A. G., Movasaghi, Z. et al., "Advances in Fourier transform infrared (FTIR) spectroscopy of biological tissues," Applied Spectroscopy Reviews, 52(5), 456-506 (2016). 